Research Article

\title{
Planning the Structure of University Teaching Staff Based on Multiobjective Optimization Method
}

\author{
Xiaoqian Zhang \\ Personnel Department of Nantong Institute of Technology, Nantong 226002, China \\ Correspondence should be addressed to Xiaoqian Zhang; 41724100@xs.ustb.edu.cn
}

Received 19 July 2021; Revised 8 August 2021; Accepted 18 August 2021; Published 24 August 2021

Academic Editor: Muhammad Usman

Copyright ( $\odot 2021$ Xiaoqian Zhang. This is an open access article distributed under the Creative Commons Attribution License, which permits unrestricted use, distribution, and reproduction in any medium, provided the original work is properly cited.

\begin{abstract}
University education is a hot topic of research in this era of outcome-based education in a learning-centric atmosphere, as people struggle for a higher quality of life and technological advancements. The key problems remain in structuring the teaching staff to achieve optimal information transmission and quality. Existing research aims to improve the quality of teaching of the staff, but majority of them fail to achieve their objectives. Multiobjective (MO) optimization has attracted researchers' interest, particularly, in the context of performance monitoring and improving teaching quality. The goal of this research is to look into techniques for improving academic accomplishment through the planning structure of university teaching staff. I have adopted the Jaynes maximum entropy principle and fuzzy entropy concept to solve the structural optimization problem in the development of teaching staff in colleges and universities. The objective function and constraints in multiobjective optimization are determined, and the multiobjective optimization issue in the development of teaching staff structure is solved using the nondominated sorting genetic algorithm (NSGA-II) multiobjective genetic algorithm. The results show that the optimized structure of the teaching staff can reflect the goal of the construction of the teaching staff in colleges and universities and provide a scientific basis for the construction and planning of the teaching staff.
\end{abstract}

\section{Introduction}

As an important part of the national innovation system, colleges and universities are the main power source to implement the strategy of rejuvenating the country through science and education and the strategy of strengthening the country through talents [1]. The level of college teachers and the degree of their enthusiasm are directly related to the quality of talented graduates and correlated to the development of colleges and universities. With the aggravation of social competition, the social demand for higher education is gradually increasing. How to improve the overall level of university teachers and the quality of personnel training and scientific research level has become a core link in the management of colleges and universities in China. In the process of teaching staff construction, the size of the team, the structure of professional title, the structure of age, and the structure of educational background will affect the level of teaching staff. According to the goal of the construction of university teachers, set by the ministry of education, the structure of university teachers should be more reasonable and standardized, and the overall quality should be greatly improved [2]. Therefore, the construction of teaching staff in colleges and universities should guide the introduction, cultivation, and use of talents through medium- and longterm planning according to reasonable indicators, to achieve the balanced optimization goal of stable scale, strong innovation ability, more teaching, and scientific research output, reasonable salary, harmonious internal relations, and strong sustainable development ability of the whole team [3]. Based on the importance of the above factors, an optimization technique is needed to achieve the goals of university teachers and improve their overall teaching quality.

Optimization is the process of finding the best solution or optimal value from a given problem. The optimization problems include looking for maximum or minimum value or using one objective or multiobjectives. Problems that have more than one objective are referred to as multiobjective optimization (MOO). This type of problem is found in 
everyday life, such as education, mathematics, engineering, social studies, economics, agriculture, aviation, automotive, and many others [4]. Based on the principles of rationality, high efficiency, and dynamic, this paper proposes a multiobjective optimization method based on fuzzy entropy, which takes advantage of the importance of professional title structure, educational background structure, and age structure in the level of teaching staff and systematically considers the collaborative optimization of each substructure [5]. To solve the multiobjective optimization allocation problem of the planning staff, this research work strives to provide a scientific basis for the planning of the goal of the construction of teaching staff in colleges and universities with the following summarized contributions [6]:

(i) Use multiobjective optimization algorithms to evaluate the system performance.

(ii) Employ maximum entropy to optimize the organization of the teaching personnel. In addition, optimize each objective function using the multiobjective genetic algorithm NS-GA-II (based on nondominated sorting).

(iii) To provide several objective functions and constraints of the teaching staff's construction from the perspectives of professional title structure, educational background structure, and age structure and to solve the multiobjective structural optimization problem in the teaching staff's structure, use the multiobjective genetic algorithm NSGA-II.

(iv) Apply the optimization model to a real-world education system.

(v) Provide efficient system operation for planning the structure of university teaching staff.

The rest of the paper is organized as follows. Section 2 represents the related work. Section 3 highlights the university education system and strategies for optimizing the structure of teaching staff, while Section 4 illustrates the simulation results and experimental analysis. This paper is concluded and research directions for future are provided in Section 5.

\section{Related Work}

University teaching capacity building, which was traditionally limited to more developed countries, is now becoming a more significant responsibility in both developed and developing countries [7]. In particular, for countries and institutions that are just getting started or striving to improve their research capability and capacity, the university teaching management expertise is critical for growing organizational research capability. Despite this, university teaching administration has been described as "uncharted territory" [5], "mostly untapped territory," and a "modestly recognized" study issue [8]. Teachers are the main allocation resources in the allocation of teachers. The in-depth analysis and mining of teachers' data and the basis of decisionmaking in education management are the basis of building a teacher allocation model. Through the analysis of teachers' data, it is necessary to accurately evaluate teachers and quantify their teaching ability to improve the quality of education and teaching, which is of great significance to teachers' personal development and students' enjoyment of high quality and good education [1]. The purpose of teacher evaluation is to provide a basis for educational decisionmaking. The evaluation results should reflect the real situation of teachers and the feedback of students. At present, the evaluation system of teachers in various regions and schools mainly quantifies the evaluation indexes of teachers first and then calculates the average score. The evaluation data come from daily surveys and questionnaires and form several simple numbers to measure teachers' teaching ability. This evaluation method is more reliable, but it does not make full use of these evaluation data. There are also a variety of research methods using a clustering algorithm to establish teacher evaluation or teaching-quality evaluation model. Multiobjective optimization [6] has been used in previous studies to overcome this challenge. Multiobjective optimization [4] is a method for finding the best solution that meets numerous goals. It can emerge as a Pareto solution [9] that consists of a group of complementary options. The researchers in [10-12] have solved multiobjective optimization in building upgrade planning problems by constructing the collection-complementary options and by employing a nondominated sorting genetic algorithm (NSGA-II) among the evolutionary algorithms. The convergence performance of NSGA-II is reduced while addressing the optimization problem with four or more objectives [1]. These research methods regard teachers as multidimensional data objects composed of multiple evaluation indexes, use clustering algorithm to get clustering results, and achieve the purpose of evaluating teachers by analyzing the distribution of evaluation indexes in clustering results. It is very important to select the elements that can accurately describe the characteristics of university teachers, which is of great significance to cultivate high-quality talents and produce high-level research results [3]. At the same time, it is one of the necessary steps to establish the index of evaluating the level of teaching staff. Usually, when evaluating the basic quality of university teachers, we need to consider several important indicators. The goal of this research is to seek optimization techniques to improve the quality of university teaching staff.

\section{University Education System and Strategies for Optimizing the Structure of Teaching Staff}

This section explains the university education system, including the roles and structures of university faculty [1]. Following that, I go over various ways for optimizing the instructional staff organization. These solutions are broken down into two categories: fuzzy set/fuzzy entropy of teaching staff organization and multiobjective optimization using a genetic algorithm. Finally, I describe a multiobjective optimization method based on a genetic algorithm that I suggested. 
3.1. University Education System. Education is a type of learning where a collective's abilities, habits, and information are passed down from generation to generation through training and education [3]. Education is the most significant thing in a person's life since it instills in them the attitudes and knowledge that will allow them to progress professionally and personally throughout their lives.

Improving the general level of university teachers and then improving the quality of personnel training and scientific research is what planning the structure of university teaching staff entails. Before I get into the details of my model, let us take a look at each person's position and structure in university teaching, as well as their academic background, age, and academic relationship [13]:

(i) $\mathrm{PhD}$ associated: $\mathrm{PhD}$ associated is full-time educational employment with a definite tenure.

(ii) Professor: professorships are full-time positions, but part-time positions are also available. Research (including publication/academic distribution requirements) and research-based teaching are the primary tasks of a professorship. Research-based public-sector consulting could be part of the job description. It could also include sharing knowledge with society, as well as taking part in public debates. Professors may also be in charge of research, course and study program administration, mentoring and supervision, and academic evaluation. In most cases, a professorship is permanent; although, in extraordinary circumstances, it may be temporary. The university determines the specific weighting of the various obligations. The relative importance of various duties may change with time.

(iii) Associate professor: the main tasks of an associate professor are research (including publication/academic communication requirements) and researchbased teaching (with related examination duties). In addition to studies and research-based teaching, the role may include knowledge sharing with society, which may include public discussion. Associate professors may also be in charge of research, course and study program management, mentoring and supervision, and academic evaluation. The specific weighting of the various obligations is determined by the university. The relative importance of the various responsibilities may change with time.

(iv) Lecturer: the lecturer role is part-time employment that focuses mostly on teaching. The goal of a lectureship is to allow lecturers with appropriate practical experience or high-level qualifications to work as lecturers. Lecturers must develop and teach courses on their own, following the university's guidelines for lecturing, exams, and other evaluations. Candidates for lectureships are evaluated based on their teaching experience. It is possible to work on a permanent or temporary basis. Within the agreed-upon framework, the particular amount of working hours and any engagement in tests, etc., are set for each semester [14].
Now, I explain different structures such as tile, education, age and academic relationship in university teaching as in Figure 1.

(i) Title structure: it refers to the proportion of professors, associate professors, lecturers, and teaching assistants in the teaching staff of colleges and universities [3]. The structure of professional titles reflects the quality of teachers and the tasks they can undertake. The grade of university teachers' professional titles reflects the academic level of teachers and the level of their teaching and scientific research ability, while the structure of professional titles can reflect the overall academic level and tasks of university teachers. Different types, different foundations, and tasks of colleges and universities have different professional title structures of teaching staff.

(ii) For colleges and universities striving to build research-oriented universities in China, the best structure of teachers' professional titles should be an inverted pyramid structure. This is because, while ensuring the quality of teaching and scientific research, we need to improve the education, teaching ability, and research level of existing teachers to optimize the promotion conditions of existing teachers' professional titles. This increases the number of professors to achieve the inverted pyramid structure standard of teaching staff title in research universities.

(iii) Educational structure: academic structure refers to the proportion of graduates with a doctoral degree, master's degree, and bachelor's degree or below. The educational background and degree of university teachers are important marks of their theoretical level, research level, and potential innovation ability. The academic structure can not only reflect the professional quality of university teachers but also indicate the potential ability of teachers and the development trend of school education and teaching level. The teaching staff of colleges and universities should be mainly composed of doctoral students and master students. Theoretically speaking, the higher the proportion of highly educated teachers in the teaching staff, the higher the quality of education and teaching and the level of research. Therefore, some high-level research universities take the doctor's degree as a necessary condition for teachers.

(iv) Age structure: it refers to the age composition of college teachers [2]. The age structure of teaching staff can reflect the vitality and potential of education, teaching, and scientific research, as well as its comprehensive strength and creativity. A reasonable age structure of teaching staff should be the balanced distribution of the number of teachers in all age groups, and the number of teachers in the best age group (36-50 years old) should be higher than that in other age groups. The age structure of 


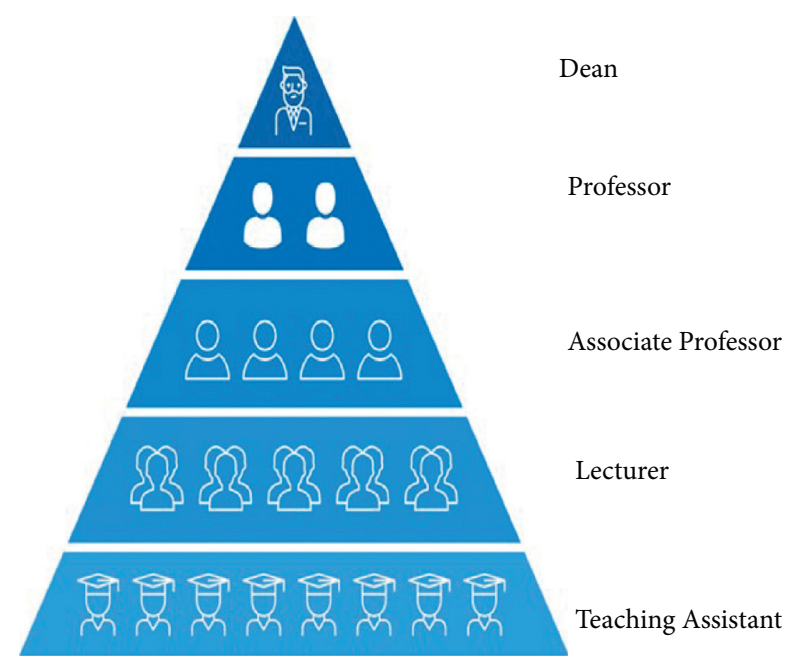

FIgURE 1: Structure of university teaching staff.

university teachers directly affects the continuity and inheritance of the team. Generally speaking, the teaching staff in colleges and universities should form a reasonable academic echelon of the old, middle age, and young, and the age distribution of the teaching staff should be in a normal curve. According to the relevant data, the proportion of teachers in different age groups is as follows: $25 \%$ are under 35 years old, $50 \%$ are $36-50$ years old, and $25 \%$ are over 51 years old. The average age of university teachers should be controlled at about 40 years old, and the average age of professors and associate professors should be controlled at 50 and 45 years old.

(v) Structure of academic relationship: it refers to the structure of the type, level, and distribution of the graduation colleges and majors of a certain degree education among the teachers in colleges and universities [1]. Promoting the optimization of the academic structure of the teaching staff and making the team members come from different regions and different types of colleges and universities, with the interdisciplinary and multitype of the professional knowledge system, will inevitably make colleges and universities have a hundred flowers blooming ideas and characteristics of education and teaching. In the analysis and evaluation of the structure of teaching staff in colleges and universities, the structure of professional title, educational background, and age are the most important factors, and these three substructures restrict each other. The optimization of one structure often means the constraint of other objectives.

According to the above, the focus of this study is on multiobjective optimization of these three substructures, to improve the structure of professional title, academic background, and age. Furthermore, the educational background and age structure should be balanced and optimized.
3.2. Strategies for Optimizing the Structure of Teaching Staff. In today's dynamic and competitive climate, strategic management is critical for educational institutions. It has been employed in a variety of quickly changing circumstances. Both are employed in the sphere of education, particularly, among university lecturers. Furthermore, the strategy implementation process, which focuses on the formation of the university's vision, mission, and teaching staff quality, is an important aspect of strategic management that is often disregarded [15]. For optimization the structure of teaching staff, I have used maximum entropy.

As per $[16,17]$, the maximum entropy principle (MEP) is a strong reasoning principle that enables one to identify the probabilities that define a system based on the information available, which is typically in the form of averages of random variables of interest. It is founded on the following principles:

(i) The system's enumeration states $\mathrm{i}=1, \ldots, \mathrm{N}$

(ii) The addition of one or more functions that convert the system's available information into probability restrictions, such as $f(p)=c$, where $c$ is a vector of average values

(iii) Develop the overall function that measures the uncertainties associated with a probability distribution candidate

Maximum entropy states that if the structure of professional title, the background of education, and the ages of teaching staff are reasonably allocated then the fuzzy entropy corresponding to the structure of these may be reaching to maximum [6]. Therefore, this paper first calculates the fuzzy entropy of title structure, education structure, and age structure and uses them as the objective function of evaluation. After that to realize the balanced optimization of each objective function, the multiobjective genetic algorithm NS-GA-II (based on nondominated sorting) is used to optimize each objective function. The Pareto optimal solution set of fuzzy entropy of each structure is obtained, to determine the balanced optimal allocation of each structure in the teaching staff.

3.2.1. Fuzzy Set and Fuzzy Entropy of the Structure of Teaching Staff. Fuzzy sets are similar to sets with pieces that have varying degrees of membership. As an expansion of the classical notion of set, fuzzy sets were developed separately in $1965[18,19]$. Entropy, on the contrary, is a measure of a system's dysfunction. Using flavors of entropy to improve algorithms ranging from decision trees to deep neural networks has demonstrated to increase speed and performance because it is much more dynamic than other more inflexible measures such as correctness or even means squared error [19]. To define JAYNES maximum entropy for the proposed system, let us assume that $\theta=\left\{\theta_{1}, \theta_{2}, \ldots, \theta_{n}\right\}$ be the parameter space corresponding to the structure state of the teaching staff $\left(p_{1}, p_{2}, \ldots, p_{n}\right)$ which is a probability distribution on it; then, the uncertainty degree of the structural state can be used as the probability distribution 
$\left(p_{1}, p_{2}, \ldots, p_{n}\right)$ expressed by the Shannon entropy defined by

$$
\sum_{i}^{n} p_{i} \ln p_{i}
$$

For the fuzzy set, let $U$ be a universe. A fuzzy set $A$ on $U$ is a mapping from $u$ to the interval $[0,1]$ such that $\mu_{A}: U \longrightarrow[0,1]$ denotes the value range. For $\mathrm{x} \in U, \mu_{A}(x)$ is called the membership of $x$ to $A$, and $\mu_{A}(\cdot)$ is called the membership function of $a$. The fuzzy entropy of fuzzy event $A$ can be defined as

$$
H(A)=-\sum_{i=1}^{n} \mu_{A}\left(x_{i}\right) \cdot p_{i} \ln p_{i} .
$$

In equation (2), $\left.p_{i}(i=1,2, \ldots, n) \mathrm{n}\right)$ is a fuzzy event $\mathrm{A}$, which has some independent probability distribution of possible states and satisfies

$$
\sum_{i=1}^{n} p_{i}=1 .
$$

From the above equation, it is cleared that a certain probability distribution $P(i=1, \cdots, n)$ can be selected to maximize the fuzzy entropy day (a) of fuzzy event $A$ so that the selected probability distribution is the minimum possible estimation based on the given information.

In order to realize the balanced optimization of multiple objectives in the teaching staff, in this research work, I have chosen the fuzzy entropy of title structure, education structure, and age structure as the objective function of multiobjective optimization. Therefore, keeping in view of the above, this paper defines the following three basic domains to plan the desired structure of university teaching staff with the help of the maximum fuzzy entropy method $[20,21]$.

Domain 1: in this domain, I define the set for title structure of the university teaching staff based on my proposed optimization method. For this purpose, the title set $U_{1}=$ \{Professor, associate professor, lecturer, teaching assistant $\}$. The number of elements $n_{1}$ of title set $U_{1}$ is 4 , that is, the cardinality of the set $\left|U_{1}\right|=4$.

Domain 2: in this domain, I have defined a set for education structure of the university teaching staff based on my proposed optimization method. Let us assume that academic degree set $U_{2}=$ ddoctor, master, undergraduate and below $\}$. The number of elements $n_{2}$ of academic degree set $U_{2}$ is 3 , that is, the cardinality of the set $\left|U_{2}\right|=3$.

Domain 3: in this domain, I have defined a set for age structure of the university teaching staff based on the proposed optimization method. Let age set $U_{3}=\{<30$, $30-40,40-50,>50\}$; the number of elements $n_{3}$ of age set $U_{3}$ is 4 , that is, the cardinality of the set $\left|U_{3}\right|=4$.

As the different professional titles, educational background and age have different effects on the level of teaching staff [22]. Therefore, I have defined three fuzzy sets below:

(i) In my scheme, the fuzzy set, $T$, represents the degree set of different professional titles, and its membership degree can be seen in the following equation:

$$
\mu_{T}(x)\left(x \in U_{1}\right)
$$

(ii) Besides fuzzy set $T$, the fuzzy set $E$ represents the degree set of different educational background, and its membership degree can be written as

$$
\mu_{E}(y)\left(y \in U_{2}\right)
$$

(iii) Similarly, fuzzy set A represents the degree set of different ages of the proposed university teaching staff, and its membership degree can written as

$$
\mu_{A}(x)\left(x \in U_{3}\right) \text {. }
$$

When the distribution of the structure of professional title, educational background, and age has been determined, then the proportion of teachers with professional title I, educational background $J$, and age $K$ is given by $P_{i j k}\left(i=1,2, \ldots, n_{1} ; j=1,2, \ldots, n_{2} ; k=1,2, \ldots, n_{3}\right)$.

Here, $P_{i j k}$ satisfies

$$
\sum_{i=1}^{n 1} \sum_{j=1}^{n 2} \sum_{k=1}^{n 3} P_{i j k}=1 .
$$

In light of equations (4)-(6), the proposed fuzzy entropy of professional title structure, educational background structure, and age structure are presented by equations (8)-(10):

$$
\begin{aligned}
& H(T)=-\sum_{i=1}^{n 1} \mu_{T}\left(x_{i}\right) \cdot\left[\left(\sum_{j=1}^{n 2} \sum_{k=1}^{n 3} P_{i j k}\right) \cdot \ln \left(\sum_{j=1}^{n 2} \sum_{k=1}^{n 3} P_{i j k}\right)\right],\left(x_{i} \in U_{1}\right), \\
& \mathrm{H}(\mathrm{E})=-\sum_{i=1}^{n 2} \mu_{E}\left(y_{j}\right) \cdot\left[\left(\sum_{i=1}^{n 1} \sum_{k=1}^{n 3} P_{i j k}\right) \cdot \ln \left(\sum_{i=1}^{n 1} \sum_{k=1}^{n 3} P_{i j k}\right)\right],\left(y_{j} \in U_{2}\right),
\end{aligned}
$$




$$
\mathrm{H}(\mathrm{A})=-\sum_{i=1}^{n 3} \mu_{A}\left(z_{k}\right) \cdot\left[\left(\sum_{i=1}^{n 1} \sum_{j=1}^{n 2} P_{i j k}\right) \cdot \ln \left(\sum_{i=1}^{n 1} \sum_{j=1}^{n 2} P_{i j k}\right)\right],\left(z_{k} \in U_{3}\right) .
$$

According to the proposed maximum entropy principle [23], if the title structure, education background structure, and age structure in the structure of university faculty reach the optimal and reasonable allocation, then the fuzzy entropy corresponding to each faculty structure reaches the maximum. This means that the multiobjective optimization model can be expressed by

$$
\text { (vp) }\left\{\begin{array}{l}
\max H=[H(T), H(E), H(A)]^{A} \\
\text { s.t. } \sum_{i=1}^{n_{1}} \sum_{j=1}^{n_{2}} \sum_{k=1}^{n_{3}} P_{i j k}=1,0 \leq P_{i j k} \leq 1 \\
\left(i=1,2, \ldots, n_{1} ; j=1,2, \ldots, n_{2} ; k=1,2, \ldots, n_{3}\right)
\end{array} .\right.
$$

3.2.2. Multiobjective Optimization Based on Genetic Algorithm. In the previous section, I have calculated the fuzzy entropy of title structure, education structure, and age structure and used them as the objective function of evaluation. Now, in this section, I explain the multiobjective genetic algorithm NS-GA-II (based on nondominated sorting) in detail to optimize each objective function.

It is difficult to evaluate the advantages and disadvantages of the solution derived from multiobjective problem objectively [24]. This is because of the mutual restriction (through the decision variables) among the objectives in the multiobjective optimization problems. At the same time, the solution of multiobjective optimization problem is not unique, but there is an optimal solution set, and the elements in the set are Pareto optimal solution or efficient solution. Furthermore, the elements in the Pareto optimal solution set are not comparable to each other for all objectives.

In this paper, I have used the NSGA-II algorithm based on Pareto optimal solution to solve the problem. Besides, the fuzzy entropy of professional title structure, academic degree structure, and age structure in the structure of university teaching staff is taken as the objective function so as to obtain the optimal allocation of professional title structure, academic degree structure, and age structure. The main steps of the proposed NSGA-II algorithm are as follows, and its flow can be seen in Figure 2.

(i) Randomly generated initial population $P_{0, t}=0$

(ii) The progeny $P_{0}$ of population $Q_{0}$ was generated, and the population size was $N$

(iii) Combine parent and offspring population, $R_{t}=P_{t} \cup Q_{t}$

(iv) Generate all nondominated fronts of $R_{t} F=\left(F_{1}, F_{2}, \cdots\right)$

(v) The congestion comparison operator $p_{n}$ is used to sort all nondominated fronts (vi) Choose $n$ best to deconstruct into new population $P_{t}+1$

(vii) A new offspring population $Q_{t}+1$ was created by selection, crossover, and mutation

(viii) $t=t+1$

(ix) If the maximum propagation algebra is reached, the algorithm is terminated; otherwise, step (iii) is executed

Figure 2 can be explained in following phases:

Phase 1: the initial parameter input is treated within the first phase. System integration parameters and NSGAII configuration parameters are among these parameters. The majority of system parameters are determined by the type of facility, technical parameters, economic parameters, system operation strategy, and so on. The size of the population (pop), the number of iterations $(\mathrm{t})$, crossover probabilities, and mutation and distribution indices of crossover and mutation procedures are among the NSGA-II parameters.

Phase 2: the second phase is about the initialization of the population which is based on the initialization in phase 1 .

Phase 3: this phase is about the operation plan and objective function, which computes the individual fitness function.

Phase 4: phase 4 reserves some of the candidate solutions according to fitness in a fresh population and rejects others.

Phase 5: phase 5 is about crossover and mutation processes. A fresh population is gained by crossover and mutation operation of population. Then, compute the individual fitness function in the population.

Phase 6: phase 6 produces a new population. The new population is attained by considering the rank value and crowding distance.

Phase 7: phase 7 is concerned with the end condition decision. When the maximum evolutionary generation is satisfied, the individual with the maximum fitness gained in the evolution procedure is taken as the optimal solution output, and the calculation is ended.

\section{Simulation Results and Experimental Analysis}

This section of the paper represents the experiments performed and the simulation results carried out via those experiments. Multiple simulation experiments were conducted to plan the university teaching structure with the help of multiobjective optimization method, i.e., maximum entropy and multiobjective genetic algorithm NS-GA-II (based 


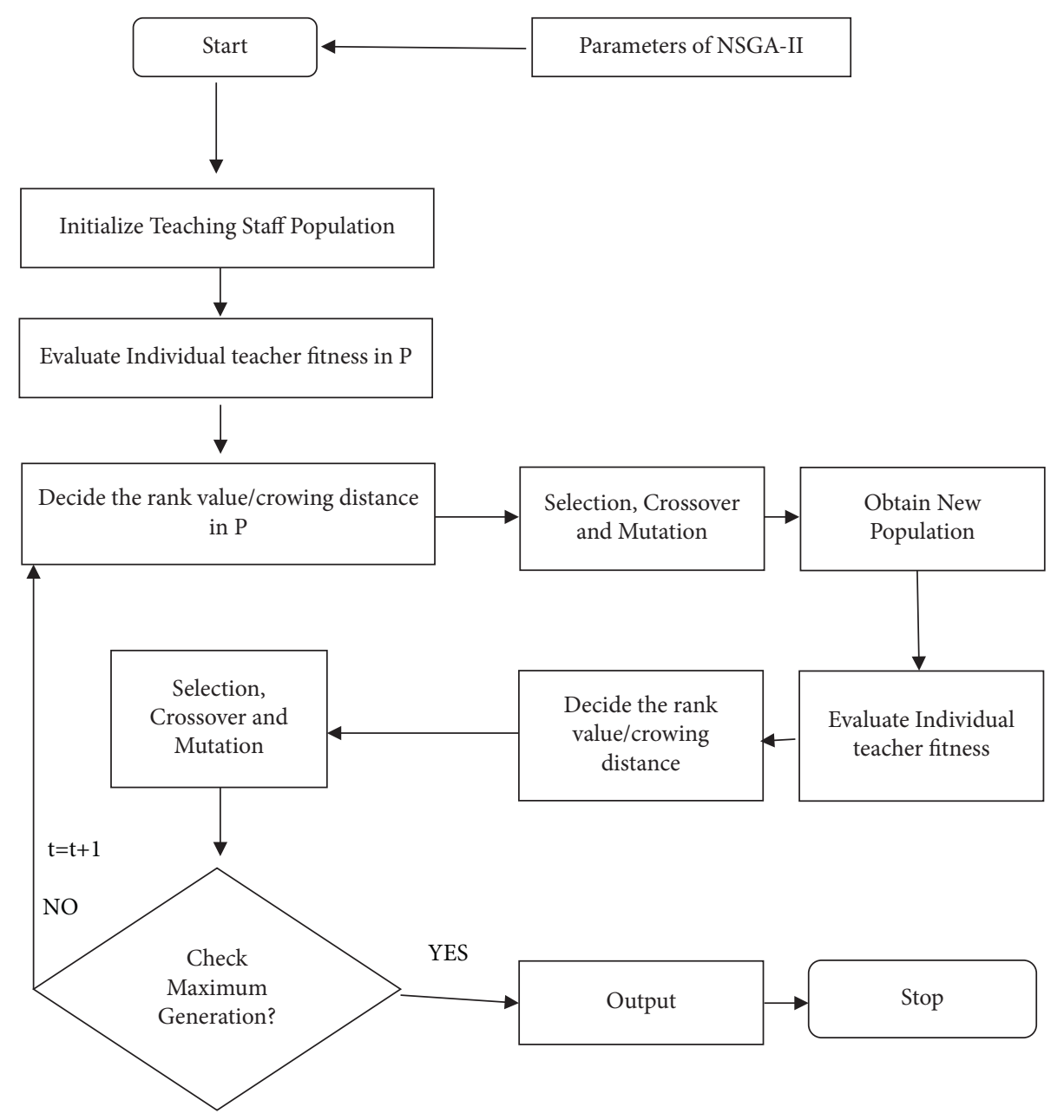

FIgURE 2: Flow diagram NSGA-II.

on nondominated sorting). I established a university teaching planning structure model for teaching staff for education sectors in real environment. Multiple experiments were performed by using various parameter settings. Among the experiments and simulation results, the top two are discussed here. All the experiments have been performed on a Laptop computer (Dell Core-i5, 7th generation, having a processor of $2.7 \mathrm{GHz}, \mathrm{RAM}$ of $32 \mathrm{~GB}$, and the operating system on which it operated was Windows 7).

4.1. Calculation Process. In the process of calculation, for the problem of membership value in maximum entropy, the membership value is obtained by questionnaire survey and fuzzy statistical method [25]. The parameters of NSGA-II algorithm are determined according to the following principles:

(i) A real parameter vector corresponds to a chromosome, and a real number corresponds to a gene

(ii) The initial value assigned to each variable is located in $[0,1]$ interval and the initial value of each variable is generated by random function (iii) The fitness function is determined according to the fuzzy entropy of professional title, education background, and age

(iv) The genetic operator, the selection operator, the crossover operator, and the polynomial mutation operator are used, respectively

(v) The population size was 1000 , the variation probability was 0.2 , the crossover probability was 0.9 , and the generation was 200

4.2. Result Analysis. In the teacher allocation model, when the search space is large and the number of iterations is limited, the algorithm is easy to fall into local optimum, so mutation operation and local search are added to the algorithm to improve the diversity of the population. As shown in Figure 3, in multiple experiments for a group of data, different thresholds are selected for mutation operation $\varphi$; the fuzzy entropy of professional title structure, educational background structure, and age structure is taken as the objective function.

According to the analysis of Figure 3, the mutation operation threshold is $0 \varphi$. This indicates that the small selection of the algorithm is not enough to increase the 


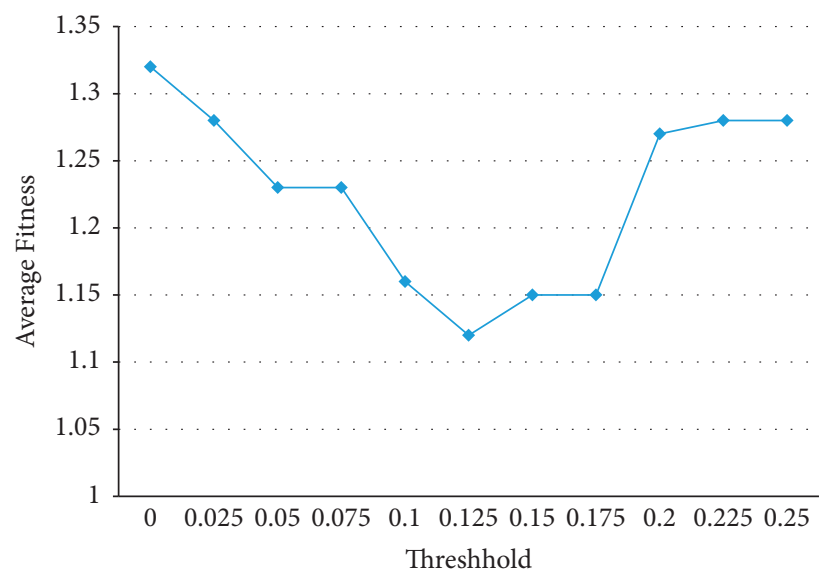

Figure 3: Influence of threshold on experimental results in mutation operation.

TABLe 1: Part of multiobjective optimization (solution 1) results.

\begin{tabular}{|c|c|c|c|c|c|}
\hline \multicolumn{6}{|c|}{ Solution 1} \\
\hline Age & Education & Professor & Associate professor & Lecturer & Assistant \\
\hline \multirow{3}{*}{$<30$} & Doctor & 1.26 & 3.53 & 3.30 & 1.90 \\
\hline & Master & 0.21 & 1.97 & 2.85 & 0.30 \\
\hline & Bachelor degree or below & 0.07 & 0.57 & 0.55 & 0.03 \\
\hline \multirow{3}{*}{$30-40$} & Doctor & 11.74 & 3.20 & 3.88 & 1.88 \\
\hline & Master & 5.12 & 0.19 & 0.61 & 0.23 \\
\hline & Bachelor degree or below & 0.10 & 0.22 & 0.04 & 0.02 \\
\hline \multirow{3}{*}{$40-50$} & Doctor & 8.06 & 8.34 & 4.82 & 4.42 \\
\hline & Master & 3.73 & 2.06 & 0.07 & 2.04 \\
\hline & Bachelor degree or below & 0.68 & 1.38 & 0.02 & 0.07 \\
\hline \multirow{3}{*}{$>50$} & Doctor & 3.61 & 3.75 & 4.55 & 1.25 \\
\hline & Master & 0.52 & 1.79 & 3.87 & 0.22 \\
\hline & Bachelor degree or below & 0.40 & 0.71 & 0.44 & 0.02 \\
\hline
\end{tabular}

diversity of the population and improve the spatial search ability of the algorithm. The BPSO with mutation operation is equivalent to random sampling when the selection is larger, and the characteristics of the algorithm itself are masked.

During the experimental work, I have selected 0.125 as the threshold of mutation operation. I have selected two groups from BPSO Pareto optimal solution, which are listed in Tables 1 and 2. According to the characteristics and rationality judgment of the optimization of the teaching staff in colleges and universities, a group of optimal solutions close to their situation can be selected as the goal of the structural planning of the teaching staff. For this purpose, I have obtained two solutions such as solution 1 and solution 2 in Tables 1 and 2, respectively. If solution 1 listed in Table 1 is selected as the result of multiobjective optimization, then the proportion of professors, associate professors, lecturers, and teaching assistants is $36.6 \%, 28.8 \%, 24.2 \%$, and $12.4 \%$, respectively.

Similarly, the solution 2 is listed in Table 2; the proportion of graduate students, undergraduate students, and junior college students is $69.5 \%, 25.8 \%$, and $4.7 \%$, respectively. The proportion of people under 30 years old, between 30 and 40 years old, between 40 and 50 years old, and over 50 years old is $16.1 \%, 27.7 \%, 35.6 \%$, and $20.6 \%$, respectively. It can be seen that the structure of teaching staff after multiobjective optimization meets the requirements of the construction of teaching staff in colleges and universities.

Figure 4 illustrates the result obtained during first solution, i.e., solution 1, of my experimental work. From this figure, it is cleared that high proportion can be achieved during the teaching staff having ages ranging 30-40 years. This proportion lies between 16 and 18; the lowest proportion was achieved below the age of 30 years.

Figure 5 illustrates the result obtained during our solution 2 of my experimental work. From this figure, it is cleared that high proportion can still be achieved during the teaching staff having ages ranging $30-40$ years. This proportion lies between 16 and 18 , the lowest proportion achieved below the age of 30 years. It is clear that proposed planning structure of teaching staff after multiobjective optimization meets the requirements of the building of teaching staff in colleges and universities. 
TABle 2: Part of multiobjective optimization (solution 2) results.

\begin{tabular}{|c|c|c|c|c|c|}
\hline \multicolumn{6}{|c|}{ Solution 2} \\
\hline Age & Education & Professor & Associate professor & Lecturer & Assistant \\
\hline \multirow{3}{*}{$<30$} & Doctor & 1.13 & 0.17 & 5.08 & 0.63 \\
\hline & Master & 0.41 & 0.10 & 1.35 & 0.46 \\
\hline & Bachelor degree or below & 0.18 & 0.02 & 1.34 & 0.50 \\
\hline \multirow{3}{*}{$30-40$} & Doctor & 10.16 & 3.83 & 10.32 & 5.18 \\
\hline & Master & 4.52 & 3.29 & 5.08 & 0.66 \\
\hline & Bachelor degree or below & 2.43 & 0.04 & 0.01 & 0.01 \\
\hline \multirow{3}{*}{$40-50$} & Doctor & 4.04 & 6.99 & 4.19 & 0.32 \\
\hline & Master & 0.96 & 2.66 & 0.93 & 0.20 \\
\hline & Bachelor degree or below & 0.09 & 0.28 & 0.25 & 0.08 \\
\hline \multirow{3}{*}{$>50$} & Doctor & 4.70 & 8.66 & 2.04 & 2.92 \\
\hline & Master & 0.17 & 0.04 & 0.59 & 1.82 \\
\hline & Bachelor degree or below & 0.02 & 0.09 & 0.30 & 0.4 \\
\hline
\end{tabular}

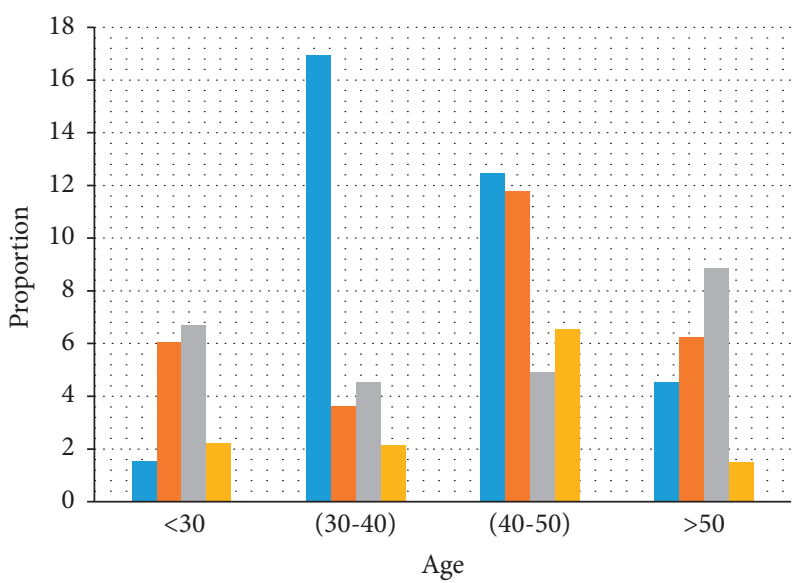

Solution 1
- Professor
- Associate Professor $\quad$ - Lecturer

FIgURE 4: Comparison of proportion of ages $>30$ to ages $<50$ for solution 1 .

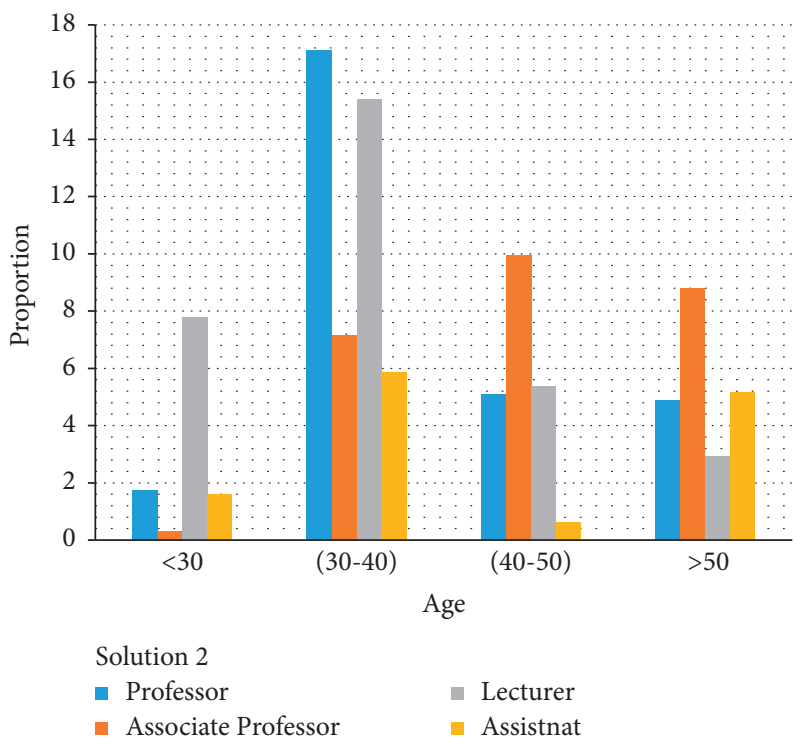

Figure 5: Comparison of proportion of ages $>30$ to ages $<50$ for solution 5 . 


\section{Conclusion}

Based on the study of the planning objectives of the construction of teaching staff in colleges and universities, this paper puts forward several objective functions and constraints for the construction of teaching staff from different aspects. These aspects include professional title structure, education background structure, and age structure. So, to solve the multiobjective structural optimization problem in the planning structure of teaching staff, this research work has used fuzzy entropy to calculate the title structure, education structure, and age structure and used them as the objective function of evaluation. Besides, I have used the multiobjective genetic algorithm NS-GA-II to optimize each objective function. My proposed system enables us to effectively improve the scientific and rationality of the construction and planning of the teaching staff by selecting the requirements of the medium- and long-term development plan of colleges and universities. My proposed system also provides a scientific basis for planning the construction goal of the teaching staff of colleges and universities.

\section{Data Availability}

The data used to support the findings of this study are included within the article.

\section{Conflicts of Interest}

The author declares that there are no conflicts of interest regarding the publication of this paper.

\section{Acknowledgments}

This work was financially supported by the Top-notch Academic Programs Project of Jiangsu Higher Education Institutions (Grant no. 2020-9).

\section{References}

[1] M. R. Nayak, C. K. Nayak, and P. K. Rout, "Application of multi-objective teaching learning based optimization algorithm to optimal power flow problem," Procedia Technology, vol. 6, pp. 255-264, 2012.

[2] S. Lin, "Reviewer Acknowledgements for Higher Education Studiesav," Higher Education Studies, vol. 8, no. 3, p. 113, 2018.

[3] S. Masino and M. Niño-Zarazúa, "What works to improve the quality of student learning in developing countries?" International Journal of Educational Development, vol. 48, pp. 53-65, 2016.

[4] H. A. Abbass, R. Sarker, and C. Newton, "PDE: a paretofrontier differential evolution approach for multi-objective optimization problems," in Proceedings of the 2001 Congress on Evolutionary Computation, pp. 971-978, IEEE, Seoul, South Korea, 2001.

[5] F. Edgar and A. Geare, "Factors influencing university research performance," Studies in Higher Education, vol. 38, no. 5, pp. 774-792, 2013.

[6] Z. Ma, P. Cooper, D. Daly, and L. Ledo, "Existing building retrofits: methodology and state-of-the-art," Energy and Buildings, vol. 55, pp. 889-902, 2012.
[7] T. L. H. Nguyen, Building university research capacity building in vietnam: prospects, problems, and possibilities, $\mathrm{PhD}$ Thesis, Melbourne Graduate School of Education, Carlton, Australia, 2013.

[8] A. Bosch and J. Taylor, "A proposed framework of institutional research development phases," Journal of Higher Education Policy and Management, vol. 33, no. 5, pp. 443-457, 2011.

[9] R. T. Marler and J. S. Arora, "Survey of multi-objective optimization methods for engineering," Structural and Multidisciplinary Optimization, vol. 26, no. 6, pp. 369-395, 2004.

[10] P. Penna, A. Prada, F. Cappelletti, and A. Gasparella, "Multiobjectives optimization of energy efficiency measures in existing buildings," Energy and Buildings, vol. 95, pp. 57-69, 2015.

[11] F. P. Chantrelle, H. Lahmidi, W. Keilholz, M. E. Mankibi, and P. Michel, "Development of a multicriteria tool for optimizing the renovation of buildings," Applied Energy, vol. 88, no. 4, pp. 1386-1394, 2011.

[12] Y. Shao, P. Geyer, and W. Lang, "Integrating requirement analysis and multi-objective optimization for office building energy retrofit strategies," Energy and Buildings, vol. 82, pp. 356-368, 2014.

[13] K. Deb, L. Thiele, M. Laumanns, and E. Zitzler, "Scalable test problems for evolutionary multi-objective optimization," Technical report, Computer Engineering and Networks Lab (TIK), Zurich, Switzerland, 2001.

[14] X. Wu, S. Zhang, Z. Gong, J. Ji, Q. Lin, and J. Chen, "Decomposition-based multiobjective evolutionary optimization with adaptive multiple Gaussian process models," Complexity, vol. 2020, pp. 1-22, 2020.

[15] M. Mišanková and K. Kočišová, "Strategic implementation as a part of strategic management," Procedia: Social and Behavioral Sciences, vol. 110, pp. 861-870, 2014.

[16] E. T. Jaynes, "Information theory and statistical mechanics," Physical Review, vol. 106, no. 4, pp. 620-630, 1957.

[17] E. T. Jaynes, Probability Theory: The Logic of Science, Cambridge University Press, Cambridge, UK, 2003.

[18] L. A. Zadeh, "Fuzzy sets," Information and Control, vol. 8, no. 3, pp. 338-353, 1965.

[19] S. Gottwald, "An early approach toward graded identity and graded membership in set theory," Fuzzy Sets and Systems, vol. 161, no. 18, pp. 2369-2379, 2010.

[20] M. Du, S. M. Wang, and G. Gong, "Research on decision tree algorithm based on information entropy," Advanced Materials Research, vol. 267, pp. 732-737, 2011.

[21] S. Li, M. Zhou, W. Meng, and W. Zhou, "A new grey prediction model for forecasting the automobiles ownership in China," Journal of Control and Decision, vol. 8, no. 2, pp. 155-164, 2019.

[22] Z. Fei, B. Li, S. Yang, C. Xing, H. Chen, and L. Hanzo, "A survey of multi-objective optimization in wireless sensor networks: metrics, algorithms, and open problems," IEEE Communications Surveys \& Tutorials, vol. 19, no. 1, pp. 550-586, 2017.

[23] F. Zou, L. Wang, X. Hei, and D. Chen, "Teaching-learningbased optimization with learning experience of other learners and its application," Applied Soft Computing, vol. 37, pp. 725-736, 2015.

[24] C. Wu, T. Wu, K. Fu et al., "AMOBH: adaptive multiobjective black hole algorithm," Computational Intelligence and Neuroscience, vol. 2017, pp. 1-19, 2017.

[25] W. Wang, S. Cao, L. Zhu, and X. Huang, "Constructing markov state models to elucidate the functional conformational changes of complex biomolecules," WIREs Computational Molecular Science, vol. 8, no. 1, p. e1343, 2017. 